\title{
Caso clínico: neumonía de comunidad grave COVID-19
}

\section{Case report: serious community pneumonia COVID-19}

Clara Serrano Ferrer ${ }^{1}$, Juan Higuera Lucas ${ }^{1}$

\begin{abstract}
In early December 2019, a group of patients with bilateral atypical pneumonia were identified in Wuhan. Later, the coronavirus 2 SARS-CoV-2 was identified as the etiological agent, which would receive the name of COVID-19. Currently, this virus is expanding worldwide, becoming a pandemic. Many of these patients require admission to intensive care units. We present the case of a patient treated and discharged from our unit. Despite not involving management that is out of the ordinary, he is a patient prototype of severe community acquired pneumonia due to coronavirus. Pneumonia that we have not faced before and that we are forced to manage in masse. At the beginning of the disease in Europe, we did not have this type of descriptions so we hope it will be helpful.
\end{abstract}

\section{RESUMEN}

A principios de diciembre de 2019 , se identificó en Wuhan un grupo de pacientes que presentaban neumonía atípica bilateral. Posteriormente, se identificó como agente etiológico el coronavirus 2 SARS-CoV-2 que recibiría el nombre de COVID-19. Actualmente, este virus presenta una expansión mundial convirtiéndose en una pandemia. Muchos de estos pacientes requieren ingreso en unidades de cuidados intensivos. Presentamos el caso de un paciente tratado y dado de alta en nuestra Unidad. Pese a no entrañar un manejo que se sale de lo normal, es un paciente prototipo de neumonía de comunidad grave por coronavirus. Una neumonía a la que no nos habíamos enfrentado hasta ahora y que nos vemos obligados a manejarla en masa. Al inicio de la enfermedad en Europa, no contábamos con este tipo de descripciones por lo que esperamos que sea de ayuda.
Key words:

Pneumonia, COVID-19

Palabras clave:

Neumonía, COVID-19

Hospital Universitario Príncipe de Asturias.

Fecha de recepción: 2 de abril de 2020

Fecha de aceptación: 6 de abril de 2020

\section{ORCID}

https://orcid.org/0000-0003-1778-2291

\section{Correspondencia:}

Juan Higuera Lucas

Email: jhiguera.151@gmail.com 


\section{Caso clínico}

A principios de diciembre de 2019 , se identificó en Wuhan un grupo de pacientes que presentaban neumonía atípica bilateral. Posteriormente se identificó como agente etiológico el coronavirus 2 SARSCoV-2 que recibiría el nombre de COVID-19. Actualmente este virus presenta una expansión mundial convirtiéndose en una pandemia. En España se detectó el primer caso el día 31 de enero en La Gomera, Tenerife. Actualmente España es uno de los países más afectados del mundo con más de 100.000 afectados y más de 10.000 muertes. Las unidades de cuidados intensivos superan su capacidad habitual en la mayoría de las ciudades españolas.

El primer caso diagnosticado en nuestro Hospital, el Príncipe de Asturias (Alcalá de Henares), fue el $6 / 3 / 2020$. El 20 de marzo se publicó la primera guía para manejo del paciente crítico por neumonía COVID-19 en la revista Intensive Care Medicine[1].

Presentamos al $5^{\circ}$ paciente ingresado y tratado en nuestra Unidad y tercer paciente en ser dado de alta. Hemos elegido este paciente porque, pese a no entrañar un manejo que se sale de lo normal, es un paciente prototipo de neumonía de comunidad grave por coronavirus. Una neumonía a la que no nos habíamos enfrentado hasta ahora y que nos vemos obligados a manejarla en masa.

Se trata de un varón de 51 años sin antecedentes de interés que acude al Servicio Urgencias Hospitalarias el día 2 de marzo por fiebre, tos y expectoración de varios días de evolución. En Urgencias no presenta hallazgos clínico-analítico-radiológicos reseñables por lo que se le da de alta en tratamiento con augmentine, hasta ese momento, la etiología de la neumonía de comunidad predominante continuaba siendo la habitual (influenza y Streptococcus pneumoniae) (Figura 1).

En domicilio, presenta empeoramiento clínico, con aparición de disnea que se hace de mínimos esfuerzos por lo que vuelve a Urgencias cuatro días más tarde. En Urgencias presenta una saturación basal medida con pulsioxímetro del $80 \%$ y tensión arterial 140/80 con una frecuencia respiratoria de 20 respiraciones por minuto con hallazgo de neumonía bilateral y positividad para PCR de COVID-19 en exudado nasofaríngeo. Ingresa en planta de hospitalización de Medicina Interna con fallo monoorgánico respiratorio, iniciándose tratamiento con lopinavir/ritonavir (kaletra) el 7/03. Ante empeoramiento de insuficiencia respiratoria con mayores necesidades de fracción inspiratoria de oxígeno $\left(\mathrm{FiO}_{2}\right)$ y trabajo respiratorio con franco empeoramiento radiológico en $<24$ horas se avisa a Medicina Intensiva. Ingresa el 8/3 en nuestra Unidad precisando intubación urgente, con diagnóstico de insuficiencia respiratoria hipoxémica grave y fracaso renal agudo oligoanúrico. Se inicia interferón beta (Figuras 2 y 3 ).

Desde el punto de vista infeccioso se trató inicialmente 3 días con ceftriaxona como tratamiento de la sobreinfección bacteriana, la pauta antibiótica se estableció inicialmente en nuestro hospital conforme a

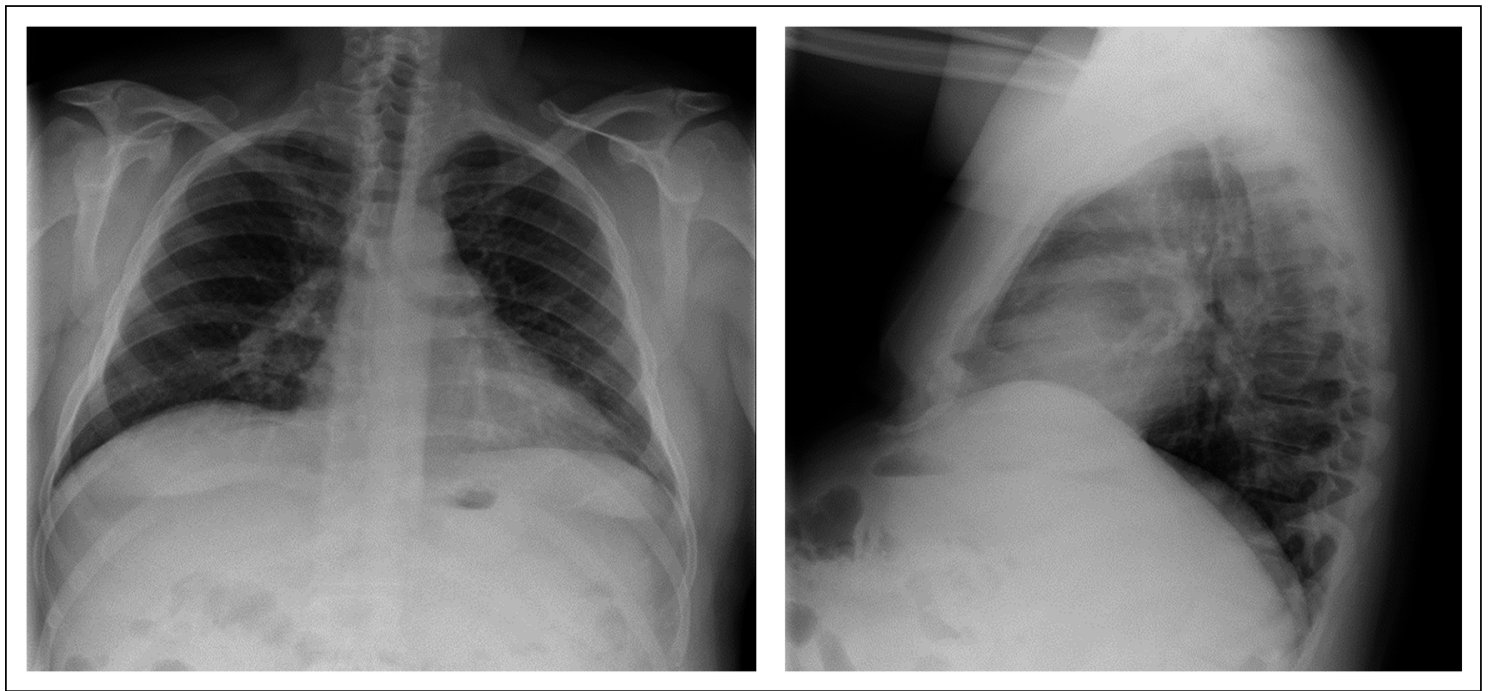

Figura 1. Infiltrados pulmonares bilaterales. 


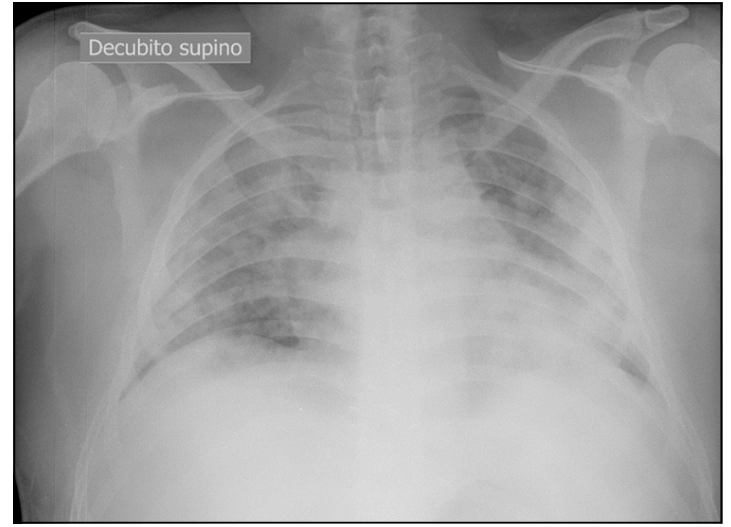

Figura 2. Infiltración severa bilateral.

las guías de manejo de la neumonía de comunidad grave por virus influenza[2]. Este apartado continúa en debate en el caso de neumonía de coronavirus. Se recomienda asociar antibioterapia tratando una posible sobreinfección durante los primeros días y desescalar en función de rastreo microbiológico, analítica y evolución. Está descrito que más del $10 \%$ de las neumonías de comunidad por coronavirus presentan sobreinfección bacteriana[3]. Tras suspensión completa de la antibioterapia basándonos en estos principios, el 13/3 presenta fiebre, leucocitosis de 15.000, pct 1,23, PCR 566 sin claro foco por lo que se inicia piperacilina-tazobactam empírico. Hemocultivos, urocultivo, aspirado pulmonar, cultivo de catéteres negativos. Se recoge nuevo aspirado de control 20/3 con aislamiento de Serratia Marcensis por lo que se desescala tratamiento a cefepime el día 23/3. Desde el día 20/3 se mantiene afebril y con leucocitos $<12.000$ y pct 0,23 (23/3).

Como tratamiento dirigido al coronavirus se mantuvieron 14 días de kaletra, interferón beta y cloroquina. Ante la ausencia de mejoría desde el punto de vista respiratorio recibe una dosis única de tozilizumab el día 13/3 (ferritina e IL6 no disponibles). Presentó fiebre mantenida en torno a $38,3^{\circ} \mathrm{C}$ los primeros 5 días, con leucocitos mantenidos $<13.000$. Para el control térmico se utilizaron metamizol y paracetamol. El tratamiento dirigido hacia el coronavirus ha sufrido modificaciones durante este mes. Este paciente recibió el tratamiento protocolizado inicial. La mayor parte de los pacientes mantienen hipertermia que hemos achacado al propio virus y a la medicación específica empleada para tratar el coronavirus tras descartar razonadamente infección. Este manejo aún se encuentra en debate[4].

En cuanto al manejo respiratorio, el paciente que

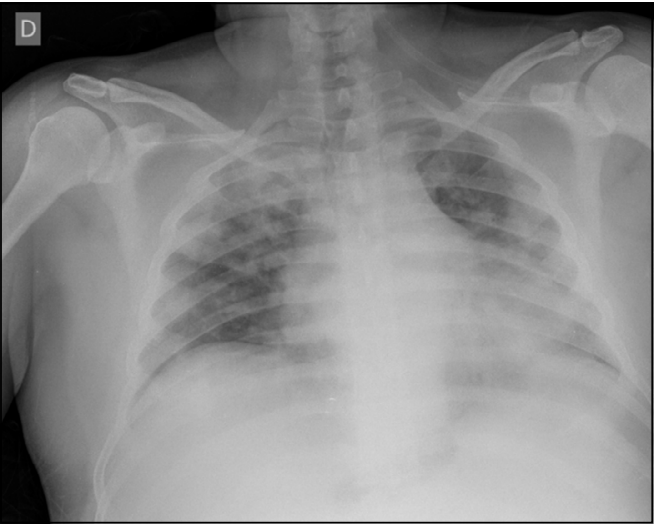

Figura 3. Infiltración severa bilateral secundaria a sobreinfección bacteriana.

presentamos (y la mayor parte de los casos ingresados en nuestro servicio), presenta una hipoxemia refractaria severa desde intubación presión arterial de oxígeno/fracción inspiratoria de oxígeno $\left(\mathrm{PaFiO}_{2}\right)$ menores de 100 . Se inicia desde ingreso relajación con perfusión de cisatracurio, se realiza maniobra de reclutamiento y se prona con lo que presenta mejoría de oxigenación. El paciente presenta buena respuesta mejorando la $\mathrm{PaFiO}_{2}$ hasta 200.

Se maneja con ventilación protectora manteniendo modalidad VC con VT $6 \mathrm{ml} / \mathrm{kg}$, PEEP 16, cabe destacar que el paciente mantiene presiones meseta por debajo de 30. La diferencia presión meseta y PEEP, se mantiene durante todo el proceso por debajo de 15. La mayor parte de estos pacientes se caracterizan por mantener buena distensibilidad pulmonar. Precisa ciclos de pronación (que se mantienen de 24 horas). Último prono el 13/3. Por problemas de abastecimiento se torna a perfusión de rocuronio el día $15 / 3$ y se suspende el 18/3. Precisa inicialmente volúmenes minuto altos para normoventilarse en torno a $14 \mathrm{~L}$ min. Como sedación, se utilizaron propofol y midazolam. Como analgesia, perfusión de cloruro mórfico. Se realiza traqueotomía percutánea el día 19/3 sin incidencias. La realización de traqueostomía percutánea precoz se basa en la polineuropatía que desarrollan los pacientes y la elevada demanda asistencial. Se inicia cambio de modalidad a presión soporte desde el 21/3 y, finalmente, se desconecta de la ventilación mecánica el día 23/3, siendo utilizada la oxigenoterapia de alto flujo como medio de desconexión intermedio. El paciente presentó como complicación neumotórax derecho sin repercusión hemodinámica con resolución tras colocación de tubo de drenaje que se retiró al alta (Figura 4). 


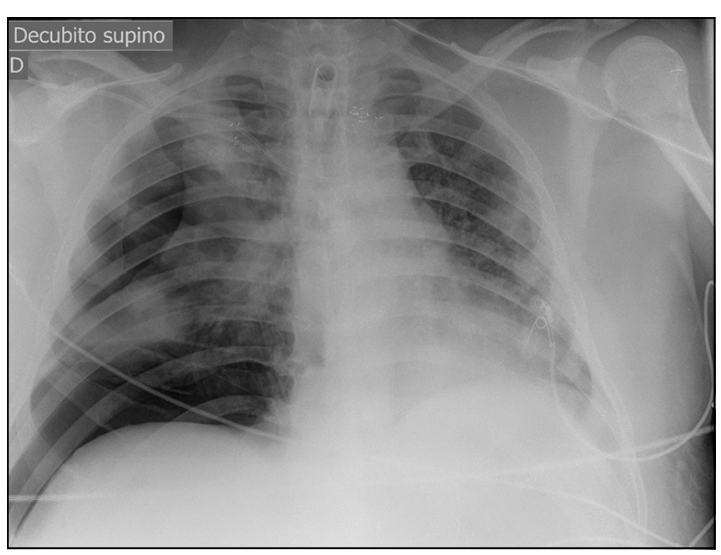

Figura 4. Neumotórax tórax derecho.

En cuanto a la fluidoterapia utilizada en el ingreso, se realizó expansión volumétrica con cristaloides inicial por presentar fracaso renal oligúrico las primeras horas. Tras normalización posterior de ritmo diurético se procuró un manejo de volumen restrictivo, iniciándose perfusión de furosemida para buscar balance acumulado neutro. Inicialmente se utilizó ácido láctico y tensión arterial media como monitoreo hemodinámico, además, de relleno capilar y exploración física habitual. Como fármaco vasoactivo se utilizó noradrenalina para alcanzar tensión arterial media de 70 mmhg, inicialmente en contexto de sedación y disminución de retorno venoso tras conexión a ventilación mecánica y días más tarde, por datos de shock distributivo tras infección. La noradrenalina fue retirada de forma completa el 18/3.

El paciente se fue de alta con la traqueostomía cerrada (abriéndose esporádicamente por broncorrea abundante), presentando polineuropatía severa en seguimiento por rehabilitación. Se mantuvo cefepime como tratamiento de neumonía asociada a ventilación mecánica tras aislamiento microbiológico mencionado quedando suspendido todo tratamiento antiviral y sin fracaso orgánico.

Hemos seleccionado este caso por ser uno de los pacientes tipo de neumonía de comunidad grave por coronavirus. Al inicio de la enfermedad en Europa, no contábamos con este tipo de descripciones por lo que esperamos que sea de ayuda.

\section{Referencias}

1. Metlay JP, Waterer GW, Long AC, Anzueto A, Brozek J, Crothers K, et al. Diagnosis and treatment of adults with community-acquired pneumonia. An official clinical practice guideline of the American Thoracic Society and Infectious Diseases Society of America. Am J Respir Crit Care Med. 2019 Oct;200(7):e45-67. https://doi.org/10.1164/ rccm.201908-1581ST PMID:31573350

2. Alhazzani $\mathrm{W}$, Møller $\mathrm{MH}$, Arabi YM, Loeb M, Gong MN, Fan E, et al. Surviving Sepsis
Campaign: guidelines on the management of critically ill adults with Coronavirus Disease 2019 (COVID-19). Intensive Care Medicine [Internet]. Springer Science and Business Media LLC; 2020 Mar 28; https:// doi.org/10.1007/s00134-02006022-5; Epub ahead of print. PMID:32222812

3. Rodriguez-Morales AJ, Cardona-Ospina JA, GutiérrezOcampo E, VillamizarPeña R, Holguin-Rivera $Y$, Escalera-Antezana JP, et al.; Latin American Network of Coronavirus Disease 2019-COVID-19 Research (LANCOVID-19). Electronic address: https://www.lancovid. org. Clinical, laboratory and imaging features of COVID-19: A systematic review and meta-analysis. Travel Med Infect Dis. 2020 Mar;101623. https://doi.org/10.1016/j. tmaid.2020.101623 PMID:32179124

4. Cao B, Wang $Y$, Wen D, Liu W, Wang J, Fan G, et al. A Trial of Lopinavir-Ritonavir in Adults Hospitalized with Severe Covid-19. New England Journal of Medicine. Massachusetts Medical Society; 2020 Mar 18; https://doi.org/10.1056/ NEJMoa2001282; Epub ahead of print. PMID:32187464 